Department of Scientific and Industrial Research : Activities in Scotland

THe view has been held by many that great benefits could accrue from the establishment of branches of the existing stations of the Department of Scientific and Industrial Research, or of new laboratories, in different parts of Great Britain. By such developments, the work of these stations could be brought more intimately before the notice of industrialists, practising engineers and others, and it would be more convenient for them to obtain the greatest benefit from the researches in progress by the most effective method - that of direct consultation and discussion with the staffs concerned. There is also the important argument that the research establishments themselves would be able more readily to appreciate the needs of industrial concerns and authorities in different places.

Accordingly, the announcement recently made concerning the establishment in Scotland of the new Mechanical Engineering Research Station and of substations for fuel, building and road research will receive wide approval. There is in Scotland, of course, a long and distinguished tradition of engineering activity of every description. In addition, there are schools of engineering science within its four universities and at various technical colleges. These schools have already established a high reputation for their teaching and for their original work; they are anxious to develop the research side of their function, and the closer contact afforded with the Department of Scientific and Industrial Research by the new developments will be helpful in this direction. Nor can it be denied that the Department itself will stand to gain from making its points of contact with all universities more numerous and more personal.

\section{New Vegetable Research Station}

THE first meeting of the governing body of the new Vegetable Research Station was held at the offices of the Ministry of Agriculture on October 8. Its incorporation as a company limited by guarantee and not having a share capital was decided on and an organising committee was set up to select suitable candidates for the post of director and to examine suitable sites for the Station; it is considered that an area of at least 300 acres would be necessary. The members of the governing body are Sir Edward Salisbury, Dr. W. G. Ogg, Prof. G. E. Blackman, Dr. H. V. Taylor, Mr. R. L. Scarlett, Dr. J. Barker, Prof. J. W. Munro, Prof. R. H. Stoughton, Prof. F. T. Brooks, Prof. T. Wallace, Prof. S. J. Watson, Prof. W. Brown, Dr. C. D. Darlington, Mr. E. H. Gardener, Mr. G. G. Hole, Mr. W. F. Swift, Mr. J: Laity, Mr. A. A. Clucas, Mr. David Lowe, Mr. J. Cracknell, Mr. F. A. Secrett and Mr. G. W. Giles.

\section{Agriculture in the Caribbean}

The Anglo-American Caribbean Commission was set up in 1942 to encourage social and economic co-operation between the United States of America and its possessions and bases in the Caribbean, and the United Kingdom and the British Colonies in the same area. In 1945, the Governments of France and the Netherlands accepted an invitation to join this body, which has since become known as the Caribbean Commission. The committee set up by its Research Council to deal with problems connected with agriculture, nutrition, fisheries and forestry has circulated a number of crop inquiries to the various agricultural departments and is issuing a series of publications based on the replies. "Grain Crops in the Caribbean", the third in the series, is now available on request from the Caribbean Research Council, Caribbean Commission, Kent House, Port of Spain, Trinidad, B.W.I. For four hundred years the agricultural systems have been largely based on single-crop agriculture for the export market. The obvious dangers of this policy and the advantages of diverse cropping have been repeatedly pointed out, and the cessation of rice imports from Burma and India during the War forced attention on the necessity for producing more food for home consumption and the desirability of encouraging inter-Caribbean trade. With the exception of rice in the Guianas and maize in British Honduras and Jamaica, both acreage and production of grain crops are normally very small. Methods of cultivation are primitive, manures are rarely used and losses are heavy owing to inadequate storage facilities. The general conclusion from the inquiry, however, is that though greater attention to fundamental research is of the utmost importance, the introduction of machinery and the application of existing knowledge could immediately bring about a substantial increase in grain production without reducing the acreage devoted to export crops.

\section{A Central Library of the World}

A PROJECT for a Central Library of the World, drawn up during the German occupation of France, with the dual objects of providing more effectively for the preservation of the documents on which human culture rests and making their utilization easier and more widespread, is of interest in relation to the programme of work now contemplated by the United Nations Educational, Scientific and Cultural Organisation, which already includes a library organisation. Of the seven stages in which it was visualized the project would be achieved, the first, that of bringing together in France a limited number of initiators, both French and foreigners resident in France, had been realized; and a second, that of formulating a concrete project and inviting the collaboration of a number of well-known French personalities, was in progress when this pamphlet was issued by the French Association for the Study of Bibliographic Questions (7 rue des St.-Pères, Paris 7), as was the fourth stage of inviting foreign co-operation. The further stages include the formation of an international committee and, after study of the problem by that committee, an international convention to set up the appropriate organisation, appoint the members and to decide on the official language to be used.

The preliminary scheme summarized in this pamphlet contemplates the establishment of the organisation, to be called the Bibliothèque Centrale du Monde, by a statute guaranteeing the absolute inviolability of the headquarters of the Organisation, which is to be regarded as a world reserve; the territory where it is located should belong to no nation. The organisation would be directed by a supreme council, and administered by an administrative council. Its director would be provided with a general secretariat and would also be responsible for the administrative, principal and auxiliary services. Besides ordinary members of council, there would be from three to ten times as many corresponding members. The supreme council would function largely through two permanent commissions, one of which would be responsible for the study of projects. The chief services contemplated 
include the deposition and distribution of documents, and diffusion of information. In particular, it is suggested that the organisation should provide at its central depot a universal primary bibliography, and should endeavour to secure the creation of a universal copyright system. It seems that with the establishment of the United Nations Educational, Scientific and Cultural Organisation, the proposals should, in the first instance, be considered by that body, presumably at the instance of one or other of the national delegations.

\section{Literature of Spectrochemical Analysis}

THE American Society for Testing Materials, through its Committee on Spectrographic Analysis, has sponsored the publication of two indexes on the literature of spectrochemical analysis. The first, issued in 1940, covered the years $1920-39$ and contained 1,467 references and a detailed subject index. The second, "Index to the Literature on Spectrochemical Analysis. Part II, 1940-1945", issued in January of this year, gives references to 1,044 publications on spectrochemical analysis that have appeared during the years $1940-45$ inclusive. In addition, there are thirty-six references, for the years 1938 and 1939, that were omitted from the earlier Index. The references are arranged in chronological order, and for each year the material is listed in alphabetical order according to the authors. English titles are given for all the papers, but foreign book titles are left untranslated. In the earlier Index abstracts were not given but only references to the published abstracts of the papers. Because of the widely scattered nature of the literature, and because many libraries probably lack complete sets of foreign periodicals for the war years, a brief abstract is provided, in Part II, for every spectrochemical publication listed. In most cases the abstracts are quoted verbatim from Chemical Abstracts, but where necessary, by consulting other abstracting journals and the original articles, a more suitable abstract has been compiled. This painstaking and intensive work, both of maintaining and compiling the Index, has been done under the direction of B. F. Scribner and W. F. Meggers, of the National Bureau of Standards, Washington. A helpful, detailed subject index, which covers the content rather than the titles of the several papers, completes the Index.

It is somewhat surprising that in spite of war-time restrictions on publication and the difficulties of access to foreign journals so much work has been done in the field of spectrochemical analysis during the War. The choice of spectrochemical methods in preference to others can only be attributed to the simplicity, speed, sensitivity and economy of these methods-all vital factors in war-time applications. With the return of industrial competition, these methods should prove equally valuable, and all spectrographers will find both Part II and the earlier Index indispensable as reference handbooks. The Index is clearly printed and bound in a paper cover, though for reference purposes in the laboratory it would have been preferable to have had a much heavier binding. Abbreviations are used extensively, and although no explanatory list is provided, no real difficulty will be experienced in understanding the text. The addition of a list of the full titles and addresses of periodicals to which reference is made would perhaps be an improvement. Copies of the Index can be obtained from A.S.T.M. Headquarters, 1916 Race Street, Philadelphia 3, Pasadena.

\section{Nature Lover: The Magazine of the Countryside}

THe recent publication of volume 4, No. 1 of Nature Lover, the magazine of the countryside, marks the revival of a much-needed popular journal which deals with the natural history and archæology of the British countryside. The greatest merit of the journal is that it chooses good, representative subject. matter which is fairly easily available, thus bringing these rural sciences within the reach of everyman. The present number contains short, readable articles on the "Unity of Nature" by C. H. Warren, "Secretive Badgers" by B. M. Nicholas, "British Fritillary Butterflies" by L. H. Newman, "Jimmy the Lizard" by Frances Pitt, "The Numbers of Animals" by Brian Vesey-Fitzgerald, "Water Problems of Fishes" by Chapman Pincher, "Some Strange Plant Habits" by Wolseley Banks, "Bird-watching on an East Coast Estuary" by R. H. Harrison, "Lavenham, Suffolk" by Geoffrey Morgan. Among these authors are some of Britain's best natural history writers, and some of the articles are illustrated by good photographs. This monthly journal can be strongly recommended to the general lay reader who is interested in country-life and natural history, and it should be encouraged in all our secondary schools, for its method of presentation is bound to stimulate interest. Subscription to Nature Lover is $16 s$. 6d. a year, including postage. Further information can be obtained from Nature Lover, Staples House, Cavendish Place, London, W.1.

\section{U.S. National Academy of Sciences : Officers}

According to the annual statement, the present officers and members of the Council of the U.S. National Academy of Sciences are as follow : President: Prof. Alfred N. Richards, professor of pharmacology, University of Pennsylvania ; Vice-President : Dean L. P. Eisenhart, Graduate School of Mathematics, Princeton University; Foreign Secretary : Prof. Detlev W. Bronk, Johnson professor of biophysies, University of Pennsylvania ; Home Secretary : Dr. F. E. Wright, Geophysical Laboratory, Carnegie Institution, Washington; Treasurer: Dr. J. C. Hunsaker, Departments of Mechanical Engineering and Aeronautical Engineering, Massachusetts Institute of Technology. Other Members of Council: Dr. Walter R. Miles, Prof. W. Albert Noyes, jun., Prof. I. I. Rabi, Dr. W. M. Stanley, Dean John T. Tate and Dr. D. D. Van Slyke.

\section{Rook Behaviour during Incubation}

CLOSELY studying a rookery of eight nests during the incubation period, C. M. Ogilvie noticed that the hen birds applied themselves almost exclusively to incubation, while excursions were rare and very brief. (British Birds, 40, No. 5 ; May, 1947.) Feeding and coition, when this occurred, took place upon the nest. The cock bird was responsible for feeding the hen, a duty which was performed with characteristic ceremony at irregular intervals; intrusions within the colony and invasions from without were combated by the male birds. Coition was more often promiscuous than between mated pairs, and took the form of an assault resisted by the hen and countered by other cocks.

\section{University of Leeds: Appointments}

THE following appointments in the University of Leeds have been announced: Mr. E. A. Vaughan, lecturer in the Department of Social Studies; Mr. 